\title{
PHYSICAL DEVELOPMENT AND PHYSICAL FITNESS OF FEMALE STUDENTS FROM THE UNWE'S BASKETBALL GROUPS
}

\author{
L. Kasabova* \\ Department of Physical Education and Sport, Business Faculty, University of National and \\ World Economy, Sofia, Bulgaria
}

\begin{abstract}
The dynamic times we live in require that curricula and scales for assessment of physical development and fitness to be updated. This circumstance gave birth to the idea of conducting our study. The research aims to analyze the changes in the characteristics of physical development and physical fitness of UNWE students. The study contingent is 110 students from the UNWE Sports Optional - Basketball groups, of which 46 are under 18, 42 are 18-20, and 22 are over 21 . At the beginning and end of the experiment, testing of key indicators of physical development and fitness was conducted. The data obtained were processed by variation analysis. The physical development of female students is the highest growth in the earliest student age. The smallest growth was at the age of 21 years, which should be taken into account in the construction of the educational process and the preparation of curricula for UNWE students. The physical fitness of female students over 21 years of age is marked to a significant decrease.
\end{abstract}

Key words: study courses, assessment, characteristics, growth

\section{PURPOSE}

Physical development, which is often the subject of scientific research, reflects the morphological, functional and psychological characteristics which determine the complex state of one's personality. For many authors, this concept includes the concept of "physical capacity", as it is the main indicator of the current physical condition of young people and students in particular. According to $\mathrm{P}$. Slanchev, physical development is "... a combination of morphological features of the body, as well as functional ones resulting from them, characterising the aspects of the shape and structure of the human body, which determine certain physical and motor skills and are related to an individual's physical capacity and health" (1, our translation).

The increase in the physical activity of students is largely related to the improvement

\footnotetext{
*Correspondence to: Larissa Kasabova, University of National and World Economy, Sofia, Business Faculty, Department of Physical Education and Sport, December 8th Blvd. Bulgaria, Student's town, Sofia -1700, phone: (+359 2) 862 90 75, GSM: (+359) 894563333, e-mail: larissa.kasabova@gmail.com
}

of their physical capacity. Proper physical development and a high degree in physical capacity are the basics of their growth as socially active individuals.

Physical capacity is a broad-spectrum concept that includes physical fitness, physical preparedness and physical condition. It is an intrinsic state of the human body, which is characterised by a certain level of motor reactions formed as a result of the functional adaptation to various biosocial influences. Physical development, gender, age and hereditary factors determine the physical capacity, which gives an idea of the overall performance of the human body.

Here, of course, the problem arises - whether this wealth of exercise and sports are rationally used to improve the health, physical development and physical capacity of our people. Unfortunately, the answer is no (2).

In this context, the optimisation of the work with students is one of the competences of the sports instructors and coaches in higher education institutions, who must not only increase the quality of their teaching methods in accordance with the modern tendencies but 
also to update in due time and adequately the standards of physical development and physical fitness which they will measure and evaluate.

The attitude of students towards sports activities in higher education institutions is also extremely important. At a young age, every individual has a problem with their lifestyle choices (3). Some authors find "a positive change in their attitude towards increased physical activity, as well as a motivation for future sports activities aimed at improving their physical fitness and quality of life". (4, our translation). A study, carried out in 2014 with first and second-year female students from the UNWE, established their attitude towards physical education and sports classes. A total of $97 \%$ of the participants in the study are clearly aware of the need and benefits of increased physical activity on their health and lifestyle. Meanwhile, half of them admit that they do not find time and motivation to practice any sports regularly. However, the share of female students willing to have physical education and sports classes throughout their studies is high, 68\%. Such a change would possibly help them improve their physical development and capacity (5). Tracking the signs of physical development has always been a task of particular importance not only for the female students participating in our study but also for the development of physical capacity.

Physical development standards need to be updated over a certain period of time. Taking into account the impact of the adverse environmental conditions, the ongoing climate changes, the geographical factor and its impact, the increasingly sedentary lifestyle and the technical advances' harmful effects among others, the physical development and physical fitness standards should include certain characteristics, distinguishing the standards for female students from the national standards. They also need to be observed during the organisation of the educational process of physical education and sports in higher education institutions. Every single human activity imposes certain requirements for the individual's physical and mental training. Therefore, the consideration of these requirements is one of the most important conditions both for mastering a certain activity and for achieving the necessary efficiency and results (6).
The results from numerous studies, dealing with the problems in physical education and sports in higher education institutions, show reduced physical activity and some existing disparities between the physical development and motor skills at this age (7). As a result of a study conducted with students from the Trakia University, G. Dyakova (2008) found that the reduced physical activity had an impact on body weight and strength endurance of the upper limbs in both sexes (8). That is why one of the main tasks of physical education and sports activities is to preserve and strengthen the students' health as it is a reflection of their mental and physical fitness (9).

Physical activity is a constant natural and biological need for an individual and their life is impossible without it. Some authors have found that the lack of it causes many negative changes in the human body, related to atrophy and reduced function of almost all organs and systems (10). Sports instructors from Trakia University have thoroughly observed students' physical parameters (11-13). The physically prepared and healthy individual is also the most capable, active and best working one. They do not get tired quickly, are rarely absent from work, are lively and motivated and are positive about the results of their work. Therefore, we believe that the physical fitness and physical development of students is an important factor for their successful work (14). The tracking of the physical development's features is a task of particular importance not only for the female students participating in our study but also for the development of physical capacity skills. There are many different studies tracking the physical development of young people. We observe that there is a significant difference between the sexes in the strength of their arms, the upper part of the body and the explosive power measured during a standing jump and with maximum touch. Men's superiority is impressive (15).

Only certain physical development features can get improved through targeted training. For instance, by increasing their body weight, an athlete is likely to become bigger and stronger, but during this period it is mandatory to conduct targeted training in order to increase their agility and speed. Faster reactions and better coordination can be achieved through agility training, but the body type cannot be 
modified and the muscle fibres cannot get contracted (16).

Physical development is very important for basketball players. The main characteristics in determining the positions in basketball are the players' physical development and acquired technical skills. Physical activity, provided through exercise and sports, can improve health and speed up the recovery of young people from accumulated fatigue (17).

Without a doubt, physical development correlates with the motor qualities and abilities of an individual and is related to the physical capacity and human health. That is why it is the subject of a large number of studies and publications (18-21).

In this regard, we measured the physical development and physical fitness of female students who attend sports - basketball classes in the specialised groups at the UNWE. Students, who have or have not played basketball in an organised group, participate in the "Optional sports - basketball" classes. When working with them, it is not necessary to achieve high sports results, but only a good level of their physical development and capacity skills necessary for their future professional training.

\section{METHODS}

The objective of the study is to use monitoring technology in order to analyse the changes, which have the same characteristics of physical development and physical fitness, in UNWE students from different age groups. To accomplish this, we set the following tasks to resolve:

1. To review the available sources.

2. To process the mathematical-statistical results obtained during our tests.

3. To analyse the dynamics of the results of the key indicators.

The subject of the study is the basic signs of physical development and physical fitness.

The object of the study is the main changes occurring in the morphofunctional features of female students within one school year and their specificities.

The study is conducted during the 2017/2018 school year. The participants in the study are 110 female students from the UNWE's "Optional sports - basketball" groups. A total of 46 of them are up to the age of 18, 42 of them are aged between 18 and 20 and 22 of them are over the age of 21 .

\section{Research Methods:}

1. Analysis of the existing literature on the subject.

2. Sports-pedagogical testing.

3. Mathematical and statistical methods.

While assessing the students' physical development, we measured the following parameters: height, weight, chest circumference, left and right-hand dynamometry. The age of the students was also taken into consideration for the purposes of the study.

While assessing the students' physical fitness, we used the following tests: standing long jump to measure the dynamic strength of the muscles; lifting the body from lying on their back to a sitting position for 30 seconds to measure the muscular strength and endurance (the body's flexor muscles); leaning forward from a sitting position with stretched arms to measure their flexibility.

We subjected the obtained data to mathematical-statistical processing through an analysis of variance.

\section{RESULTS}

The change in height in female students (Figure 1) is as follows: the highest annual increase of $1.8 \mathrm{~cm}$ occurs in students at the age of 17. The 18-year-old ones are a subject of a $1-\mathrm{cm}$ increase in their height. Between the age of 19 and 20, the increase is $0.9 \mathrm{~cm}$ per year. Students at the age of 21 and above experience the lowest increase in their height, $0.2 \mathrm{~cm}$ and $0.1 \mathrm{~cm}$ respectively, which practically remains almost the same.

In general, the changes in weight (Figure 2) in female students were insignificant. The weight of the students from the different age groups is a subject to minimal changes with an increase of $0.2 \mathrm{~kg}$ for 17 -year-old ones. The 18-year-old students experience the smallest increase in their weight, $0.1 \mathrm{~kg}$ per year. 19-year-old female students gain $0.3 \mathrm{~kg}$ per year. The 20 year-old students gain $0.4 \mathrm{~kg}$ annually, while at the age of 21, the increase in weight annually slightly decreases by $0.03 \mathrm{~kg}$. Female students over the age of 21 experience the greatest annual weight gain of $0.45 \mathrm{~kg}$. According to us, the difference in the changes in weight between the different age groups is a consequence of their considerable workload, poor eating habits and sedentary lifestyle. 


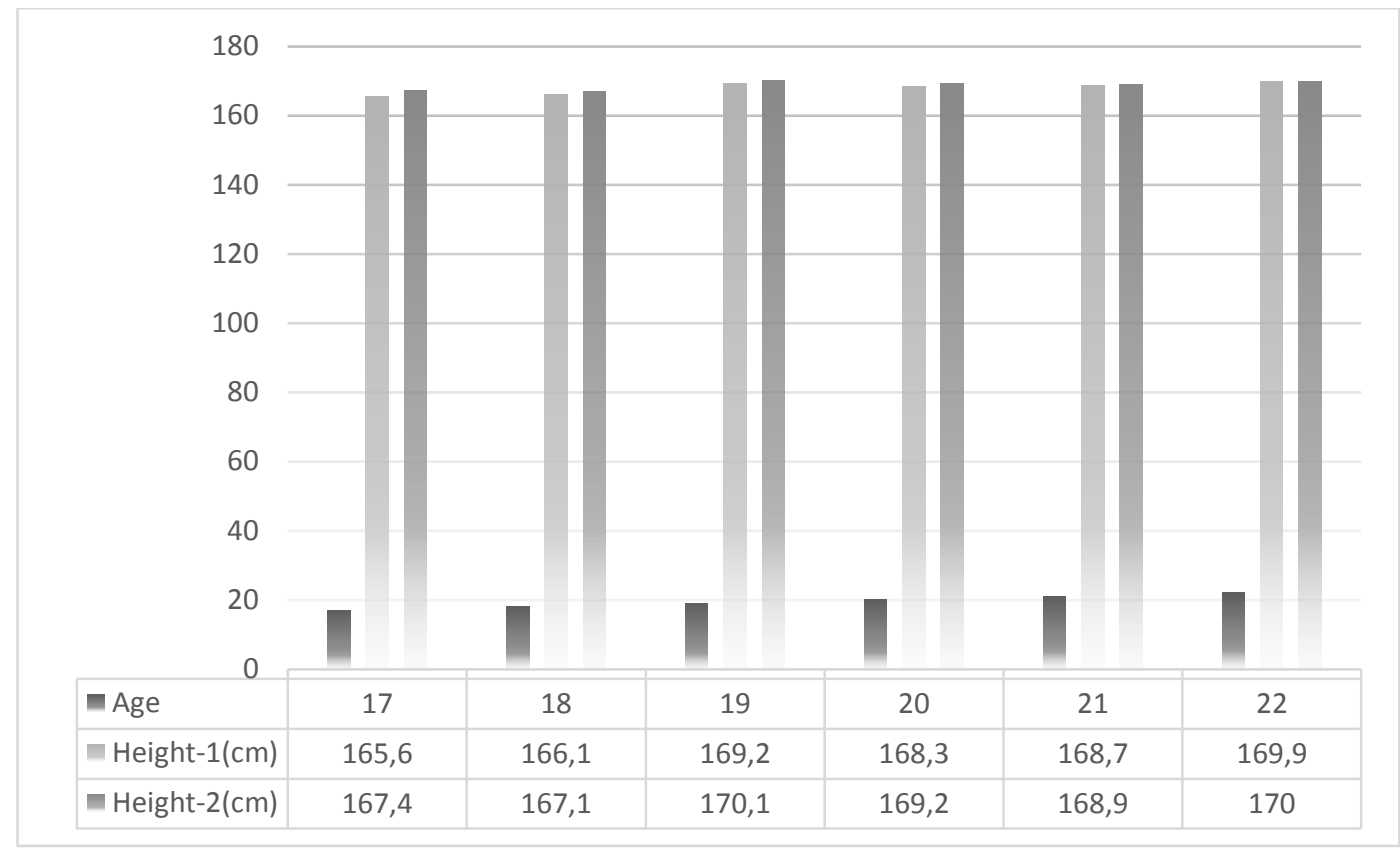

Figure 1. Dynamics of the changes in height

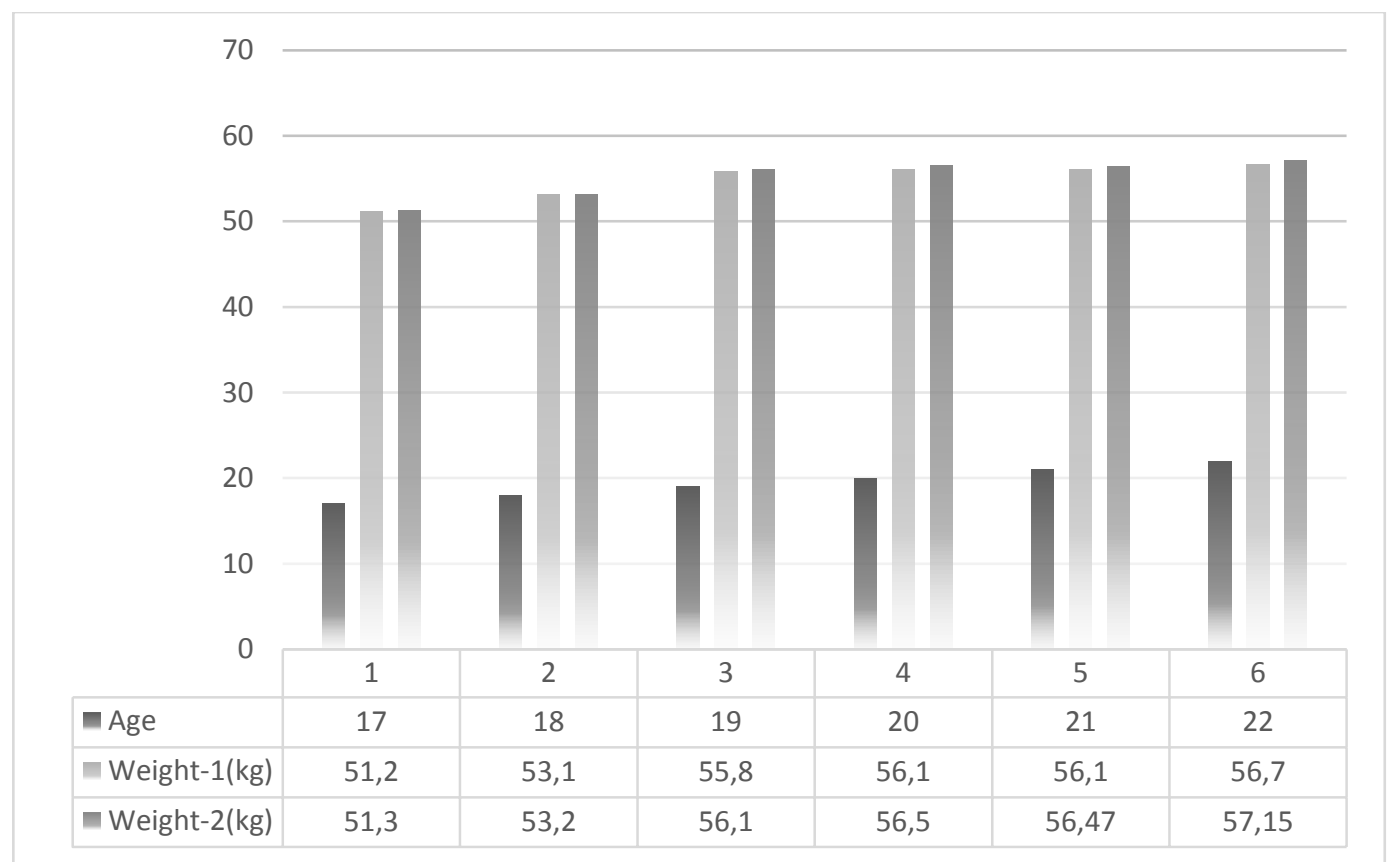

Figure 2. Dynamics in the changes in weight

The changes in the chest circumference (Figure 3) are as follows: the chest circumference of 17-year-old students increases by $1.1 \mathrm{~cm}$ per year, while the increase experienced by 18 -year-old ones is the slightest, only $0.9 \mathrm{~cm}$. At the age of 19 , the chest circumference increases by as much as $5.6 \mathrm{~cm}$ and at the age of 20 , the increase is 3.7 $\mathrm{cm}$ in one year. 21-year-old students experience an increase by $3.2 \mathrm{~cm}$, while the chest circumference of those over the age of 21 years increases only by $1.8 \mathrm{~cm}$.
The dynamics of the changes in the characteristics of the left and right-hand dynamometry are illustrated in Figure 4. The most significant increase in the left and right hand is observed between the age of 17 and 18, $0.5 \mathrm{~kg}$ for the left hand and $0.7 \mathrm{~kg}$ for the right one respectively. We observed that the changes in the strength of the palm's muscles in the right hand tend to increase until the age of 20 . The most significant increase of $3.5 \mathrm{~kg}$ is between the age of 19 and 20. The increase after this age is insignificant. The annual increase over the age of 20 is $0.2 \mathrm{~kg}$. 


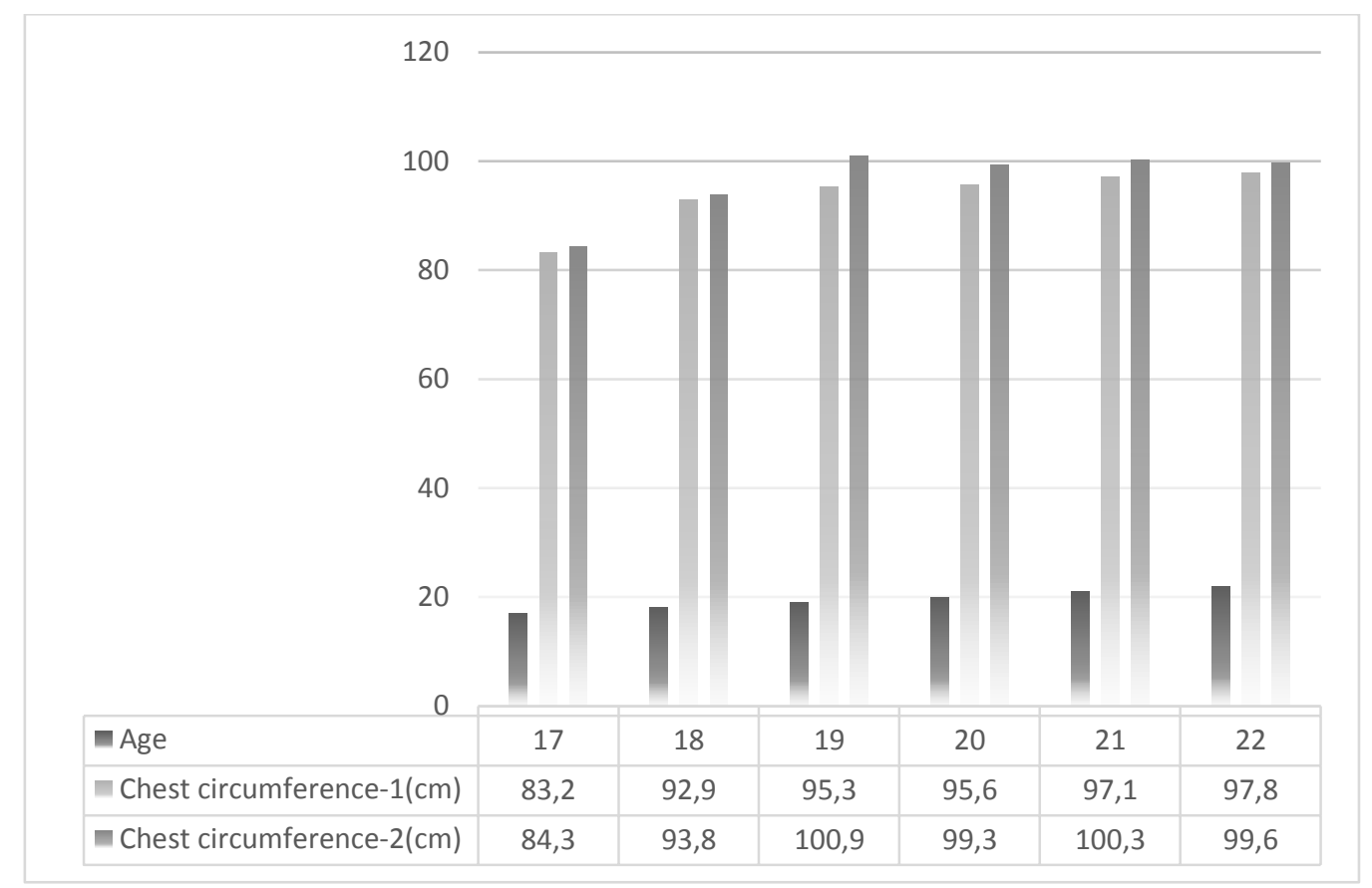

Figure 3. Dynamics in the changes in chest circumference

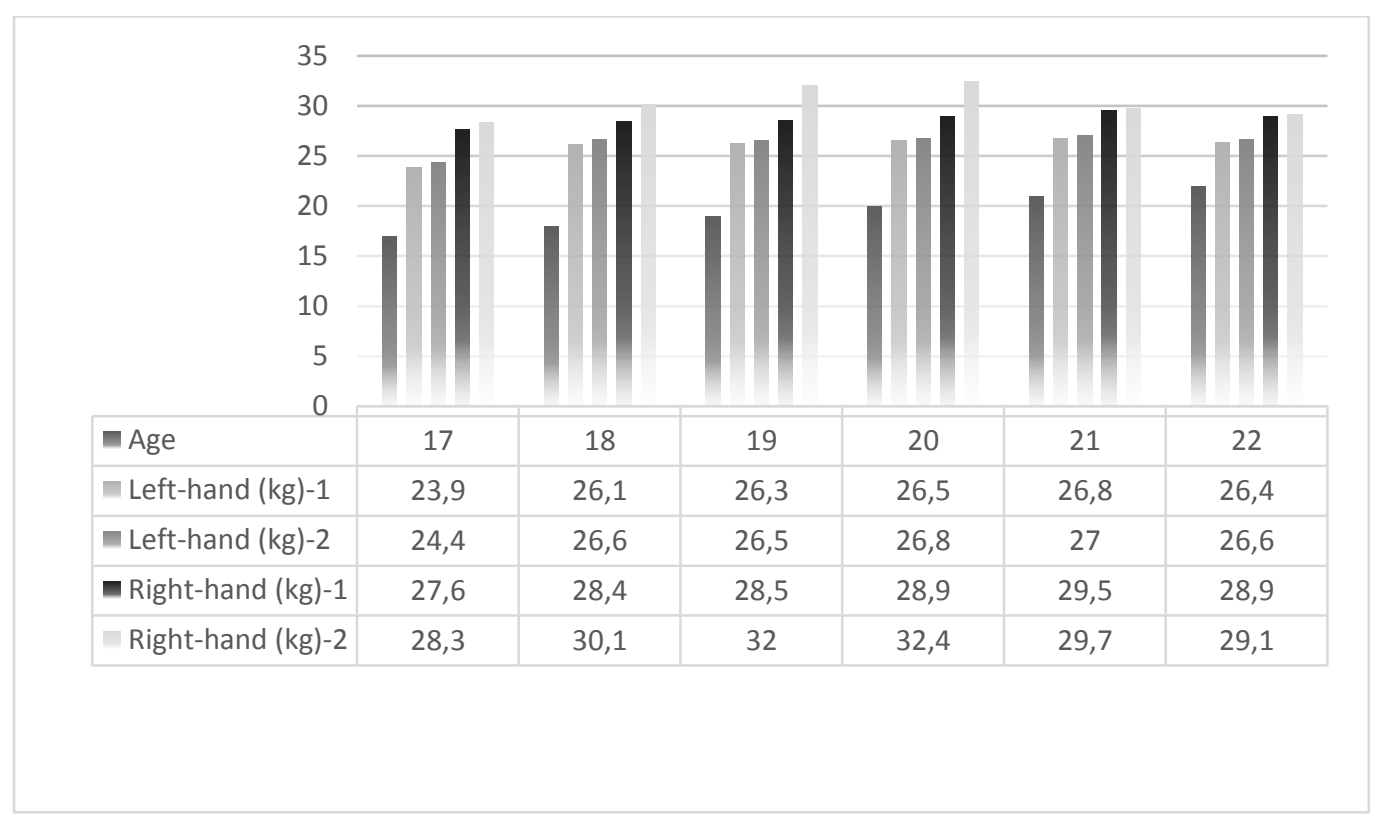

Figure 4. Dynamics in the changes in left-hand and right-hand dynamometry

While examining the change in the flexibility of the spine and the hip joints, we noticed three main stages of significant (between the age of 17 and 19), moderate (at the age of 20) and low increase (at the age of 21 and above). During our analysis of the changes occurring in the torso's muscular strength and endurance of our study's participants (Figure 5), we observed the following trend: as the age increases, the increase in it decreases. The biggest increase of 7.6 times occurs at the age of 17, the 18-year-old students experience an increase of 5.9 times and the increase is by 5.1 times at the age of 19. The increase is

moderate at the age of 20 , namely 3.5 times, while 21-and 22-year-old students experience an increase of 2.4 times and 1.8 times respectively.

The study of the dynamic strength of the lower limbs' muscles can be provisionally divided into 2 stages, namely moderate development until the age of $18(5 \mathrm{~cm}-13 \mathrm{~cm})$ and a second stage after the age of 19 when there is no development or development of under $1.5 \mathrm{~cm}$ per year. 


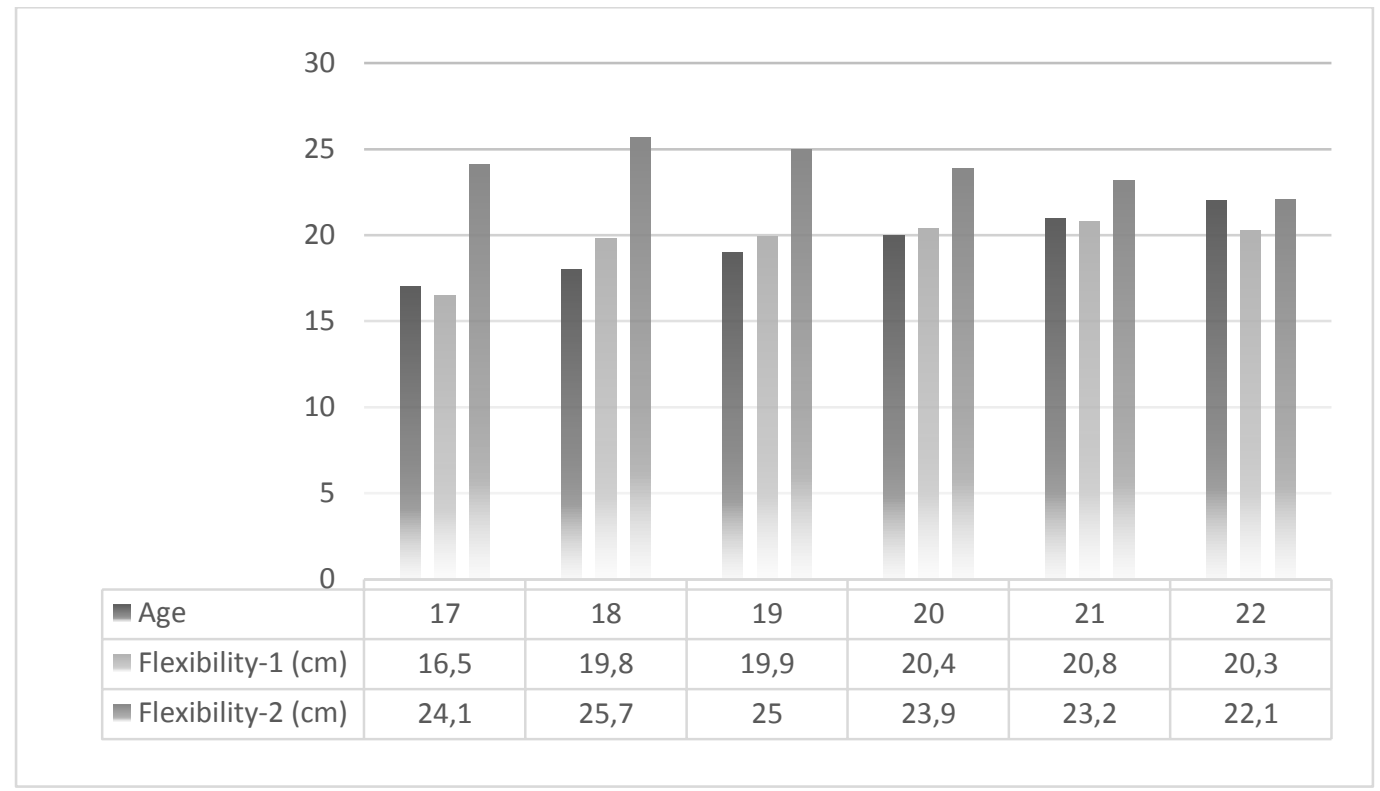

Figure 5. Dynamics of the changes in flexibility

Taking into consideration the obtained data on the physical development of female students, we need to point out that; in general, the changes in their dynamics can be divided into 3 periods. The highest growth was observed between the age of 17 and 18 and the lowest one occurred at the age of 21 . We believe that this should be taken into account when preparing and organising the teaching process and curricula.

Furthermore, the analysis of the changes in the characteristics of UNWE female students' physical fitness shows that, similarly to the ones of physical development, there are three stages in their dynamics. The first stage at the age between 17 and 18 is characterised by a moderate increase in their results. The second stage at the age between 19 and 20 marks a slight increase in their physical fitness. Finally, during the third stage over the age of 21, there is a significant decrease in female students' physical fitness.

\section{CONCLUSIONS}

1. The analysis of the changes in the physical development and physical fitness of female students in economics is a promising and viable direction for the improvement of the educational system in physical education and sports in higher education institutions.

2. The physical development of female students can be divided into three age categories and the highest growth can be observed at the earliest age.

3. The physical fitness of female students over the age of 21 marks a significant decrease. We attribute the latter to the students' sedentary lifestyle, increased workload, bad habits, increased use of technical advances, lack of physical activity, unbalanced diet, etc.

\section{REFERENCES}

1. Slanchev, P., Physical development, physical capacity and neuropsychological reactivity of Bulgaria's population. National Survey (1980-1982), NSA - IPB, Sofia, 1992.

2. Stoqnova, S., Study of the attitude of students from UNWE to the ROWFIT program. ECR reports. Contemporary trends and innovations in physical education and sports in higher education institutions. UNWE, pp.197-202, 2020.

3. Georgiev Zh., Guidelines for the development of innovations for the improvement of the programme in physical education and sports at the University of Forestry. Ed. Neofeedbeack, Sofia, p. 58, 2020.

4. Ignatova, M., P. Dikova. Study of the attitude of students at the University of National and World Economy for the physical education and sports classes. Research in kinesiology. International Journal of Kinesiology and Other Related Sciences, Vol. 46 No 1-2. pp. 33-35, 2018.

5. Milanova St., E. Tosheva, P. Milanova. Is female students' motor activity sufficient? ECR reports. Contemporary trends and innovations in physical education and sports in higher education institutions. UNWE, pp. 261-27, 2014. 
6. Aleksieva, M., Kirov, D. Analysis of the ego-orientation and the collective orientation of basketball players. Pedagogical Almanac, Pedagogical Journal of the University of Veliko Tarnovo St. Cyril and Methodius, Veliko Tarnovo, ed. issue 1, pp. 71-91, 2019.

7. Milanova, St., Ignatova, M. Study of the changes in the anthropometric indicators at female students who do not practise sports. Sports \& Science Magazine, S., N5-6, p. 143, 2016.

8. Dyakova, G. Exploring the relations between reduced physical activity physical qualities and students' morphofunctional indicators. Sports \& Science Magazine, S., No1, pp. 116-121, 2008.

9. Dikova, P. A study of the physical fitness of students aged 12-13. International Congress of Applied Sports Science. Balkan Scientific Congress Physical Education, Sports, Health, pp. 15-16 November 2019. Proceeding book. pp. 418422, 2019.

10.Peltekova, I. Research of the physical development of basketball students from Sofia University St. Kliment Ohridski. Trakia Journal of Sciences, Vol. 17, Suppl. 1, pp. 742-746, 2019, doi:10.15547/tjs.2019.s.01.120

http://www.uni-sz.bg, 2019.

11.Dyakova, G. and Petkov, P., Comparing the physical fitness indicators in students, Collection of Reports, Pedagogical Education - Traditions and Modernity, VTU, pp. 20 - 21 November, ISBN 978619-7281- 01-9, 2015.

12.Petkov. P. and Angelova, P., Examination of the physiometric indicators in students. Sessions schedule \& abstracts, 2018 Ruse, Razgrad, Silistra, FRI-2G.104-1-HC06, pp. $270-271,2018$.
13.Dyakova, G. Textbook on physical education and sports. Tr .U - press, p. 120, 2013.

14.Peltekova, I., Ignatov, G. Physical preparation results indicators and physical development of students from Sofia University - Republic of Bulgaria. Research in kinesiology, International Journal of Kinesiology and Other Related Sciences. RIK Vol.45; No1, pp. 49-52, 2017.

15.Peltekova, I., Interpretation of the results of the test battery SPARQ for basketball players. Second International Conference, Optimisation and innovation in the training process, ISSN 1314-2275, Sofia, Ed. St. Kliment Ohridski, pp. 177-184, 2010.

16. Borukova, M., Control of the sports preparedness of female basketball players at the age of 13-14, Sofia, Bolid ins, pp. 17, 2018.

17.Peltekova, I.. University basketball. Ed. St. Kliment Ohridski, pp. 82, 2020.

18.Tsarova-Vasileva, A., Borukova, M. Comparative analysis of the physical development and the specific working capacity of students from the profiled basketball groups of the Technical University (Sofia) and Sofia University. Sports \& Science Magazine, LII, S., special edition N 4, pp .87-93, 2008.

19.Tsarova-Vasileva, A. Impact of practising different types of sports on the physical development and working capacity of students. Ed. Trud, VTU, Veliko Tarnovo, 2013.

20.Tsarova, R. Problems of taking control in basketball. Monograph, Bolid Ins, Sofia, 2013.

21. Mavrudiev, P. Comparative analysis of the physical development of female students. // Sports \& Science Magazine, S., N 6, pp. 188-198, 2018. 